\title{
THE EFFECT OF MICROALLOYING WITH CHROMIUM, HAFNIUM AND YTTRIUM ON THE STRUCTURE AND MECHANICAL PROPERTIES OF THE VT18U HIGH-TEMPERATURE TITANIUM ALLOY
}

\author{
A. G. Illarionov ${ }^{1 *}$, A. A. Popov ${ }^{1}$, S. M. Illarionova ${ }^{1}$, D. V. Gadeev ${ }^{1}$, O. A. Elkina ${ }^{2}$ \\ ${ }^{1}$ Ural Federal University, Mira st. 19, 620002, Ekaterinburg, Russia \\ ${ }^{2}$ M.N. Miheev Institute of Metal Physics, Ural Branch of Russian Academy of Sciences, \\ 18 S. Kovalevskoy st.,, 620990, Ekaterinburg, Russia \\ *Corresponding author. E-mail: a.g.illarionov@urfu.ru; \\ address for correspondence: Mira st. 19, 620002, Ekaterinburg, Russia. \\ Tel.: +7 (343) 3754695
}

\begin{abstract}
The effect of microalloying of the VT18U high-temperature near-alpha titanium alloy with rare-earth elements (yttrium and hafnium), simultaneously with chromium, on its phase composition, structure and microindentation hardness is considered. It is demonstrated that additional alloying of the alloy both with chromium and hafnium and with chromium and yttrium decreases the beta-transus temperature (BTT) of the alloy. A higher content of $\beta$-stabilizers in the experimental alloys in comparison with the commercial alloy proves to increase the $\beta$-phase volume fraction and decrease the elastic modulus from $115 \mathrm{GPa}$ to $104 \mathrm{GPa}$ in the as-received $750{ }^{\circ} \mathrm{C} \alpha+\beta$-annealed condition. Additional microalloying with chromium and yttrium is shown to inhibit the $\beta$-grain growth during high-temperature holds due to the segregation of yttrium atoms to the boundaries followed by a decrease in free energy, whereas doping with chromium and hafnium proves to have no effect on the grain growth process due to the non-horophilic nature of these elements.
\end{abstract}

Keywords: microalloying, titanium alloys, rear-earth elements, REM, yttrium

DOI: $10.17804 / 2410-9908.2017 .3 .015-022$

\section{References}

1. Khorev A. I. Theory and practice of microalloying of pseudo- $\alpha$ - and $\alpha+\beta$-titanium alloys with REM, zirconium, hafnium and rhenium. Tekhnologiya mashinostroeniya, 2015, no. 1, pp. 5-10. (In Russian).

2. Nochovnaya N.A., Khorev A.I., Yakovlev A.L. Perspectives of Alloying Titanium Alloys with Rare Earth Elements. Metal Science and Heat Treatment, 2013, vol. 55, iss. 7-8, pp. 415-418. DOI: $10.1007 / \mathrm{s} 11041-013-9646-0$.

3. Cui W.F., Liu C.M., Zhou L., Luo G.Z. Characteristics of microstructures and second-phase particles in Y-bearing Ti-1100 alloy. Materials Science and Engineering A, 2002, vol. 323, iss. 1-2, pp. 192-197. DOI: 10.1016/S0921-5093(01)01362-4.

4. $\quad$ Zeng L., Hong Q., Zhao Y., Qi Y. Influence of rare earth element Y on the thermal stabilities of Ti-600 alloy. Rare Metal Materials and Engineering, 2014, vol. 43, no. 10, pp. 2407-2410.

5. Huang Z.W. Thermal stability of $\mathrm{Ti}-44 \mathrm{Al}-4 \mathrm{Nb}-4 \mathrm{Hf}-0.2 \mathrm{Si}-1 \mathrm{~B}$ alloy. Intermetallics, 2013, vol. 37, pp. 11-21. DOI: 10.1016/j.intermet.2013.01.011.

6. Kashchuk V.A. Vliyanie perekhodnykh metallov na svoistva metallov $i$ splavov [The Influence of Transition Metals on the Properties of Metals and Alloys]. Tomsk, Tomsk University Publ., 1981, 272 p. (In Russian).

7. Terekhova V.F., Savitsky E.M. Ittriy [Yttrium]. Moscow, Nauka Publ., 1967, 270 p. (In Russian).

8. Khorev A.I. Alloying titanium alloys with rare-earth metals. Russian Engineering Research, 2011, vol. 31, iss. 11, pp. 1087-1094. DOI: 10.3103/S1068798X11110104. 
9. Khorev A.I. Microalloying of titanium alloys. Metal Science and Heat Treatment, 1979, vol. 21, iss. 12, pp. 927-931. DOI: 10.1007/BF00706629.

10. Rath B.B., McDonald B.A., Sastry S.M., Lectench R.Y., O'Neal G.E., Whitesett C.R. Influence of erbium and yttrium addition on the microstructure and mechanical properties of titanium alloys. In: Titanium 80, Proc. 4th Int. Conf. on Titanium, New York, 1980, pp. 1185-1196.

11. Ilyin A.A., Kolachev B.A., Polkin I.S. Titanovye splavy. Sostav, structura, svoistva. Spravochnik [Titanium Alloys. Composition, Structure, Properties. Reference Book]. Moscow, VILS-MATI Publ., 2009, 520 p. (In Russian).

12. Gadeev D.V., Illarionov A.G., Popov A.A., Ryzhkov M.A., Kolosova E.V., Popova M.A., Altman P.S., Bondaryuk N.N. Application of the thermal analysis method to the determination of the complete polymorphic transformation temperature for a two-phase titanium alloy. Titan, 2010, vol. 1, pp. 24-30. (In Russian). 
Подана в журнал: 19.07 .2017

УДК 669.017.1

DOI: $10.17804 / 2410-9908.2017 .3 .015-022$

\title{
ВЛИЯНИЕ МИКРОДОБАВОК ХРОМА, ГАФНИЯ И ИТТРИЯ НА СТРУКТУРУ И СВОЙСТВА ЖАРОПРОЧНОГО ТИТАНОВОГО СПЛАВА ВТ $18 У$
}

\author{
А. Г. Илларионов ${ }^{1 *}$, А. А. Попов ${ }^{1}$, С. М. Илларионова ${ }^{1}$, Д. В. Гадеев ${ }^{1}$, О. А. Елкина ${ }^{2}$ \\ ${ }^{1}$ УрФУ имени первого Президента России Б.Н. Ельциина, ул. Мира 19, Екатеринбург, Россия \\ ${ }^{2}$ Федеральное государственное бюджетное учреждение науки Институт физики металлов \\ имени М.Н. Михеева Уральского отделения Российской академии наук, \\ ул. Софьи Ковалевской 18, Екатеринбург, Россия

\begin{abstract}
*Ответственный автор. Электронная почта: a.g.illarionov@urfu.ru; адрес для переписки: 620002, Екатеринбург, ул. Мира, 19, Россия. Телефон: +7(343) 375-46-95
\end{abstract}

В работе исследовано влияние микролегирования редкоземельными элементами гафнием и иттрием совместно с хромом на формирование фазового состава, структуры и

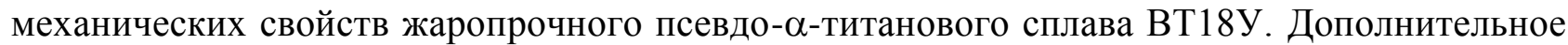
легирование исследуемого сплава обеспечивает снижение температуры $\alpha+\beta \rightarrow \beta$-перехода $\left(T_{\text {пп }}\right)$. Выявлено, что более высокое содержание $\beta$-стабилизаторов по сравнению с промышленным сплавом в исходном состоянии после отжига в двухфазной $\alpha+\beta$-области $\left(750{ }^{\circ} \mathrm{C}\right)$ обеспечивает получение большего количества $\beta$-фазы в структуре и снижение модуля упругости с 115 ГПа до 104 ГПа. Обнаружено, что после $\beta$-отжига при $1050{ }^{\circ} \mathrm{C}$ в течение 1 ч минимальный размер $\beta$-зерна фиксируется в сплаве с хромом и иттрием, т. е. микролегирование сплава ВТ18У иттрием и хромом способствует замедлению роста зерна при высокотемпературных выдержках. В свою очередь дополнительное легирование сплава хромом и гафнием практически не дает модифицирующего эффекта из-за отсутствия в этой паре сильных горофильных элементов.

Ключевые слова: микролегирование, титановые сплавы, редкоземельные элементы, РЗМ, иттрий

\section{1. Введение}

Введение в промышленные жаропрочные титановые сплавы дополнительных легирующих добавок переходных металлов, включая РЗМ, направлено на повышение термической стабильности структуры и комплекса свойств [1-5]. В качестве таких добавок могут выступать в частности иттрий $[3,4]$, гафний и хром $[5,6]$. Иттрий, находясь в твердом растворе как поверхностно-активный элемент [7] преимущественно обогащает границы зерен, что способствует закреплению вредных примесей в комплексы с ним [8]. Это приводит к рафинированию матрицы и торможению роста зерна при нагреве в $\beta$-область [9]. Также добавка иттрия в сплавах титана способствует управлению процессами распада при термической обработке [8, 9], обеспечивает повышение эксплуатационных характеристик, таких как жаропрочность [3], конструкционная прочность [9, 10], термическая стабильность [4]. Добавка гафния способствует повышению прочностных свойств титана и практически не снижает характеристики его ударной вязкости [6]. Хром, являясь сильным $\beta$-стабилизатором, при малых добавках способствует повышению температуры рекристаллизации титана [6], что благоприятно с точки зрения повышения термической стабильности сплава. Однако практически нет данных о совместном влиянии небольших добавок хрома с иттрием и хрома с гафнием на развитие 
фазовых и структурных превращений в жаропрочных сплавах титана, например, в псевдо- $\alpha-$ сплаве ВТ18У, используемом в качестве материала для изготовления деталей газотурбинных двигателей [11]. В связи с этим в работе исследовано влияние комплексных добавок хрома с гафнием и хрома с иттрием на формирование структуры, фазового состава и физикомеханических свойств в листовых полуфабрикатах из жаропрочного титанового сплава типа BT18У.

\section{2. Материал и методика исследований}

Материалом для исследования служил промышленный псевдо- $\alpha$-титановый сплав ВТ18У следующего состава (в мас. \%) Ti-6,5 A1-4,0Zr-3,0Sn-1,0Nb-0,7Mo-0,2Si (сплав 1) и опытные сплавы на основе ВТ18У с добавками: $0,7 \% \mathrm{Cr}$ и 0,15\% Hf (сплав 2); 0,6 \% Cr и 0,03 \% Y (сплав 3). Изучаемые полуфабрикаты представляли горячекатаные листы толщиной 2 мм, подвергнутые вакуумному отжигу при $750{ }^{\circ} \mathrm{C}$ в течение 1 ч.

Методами исследования служили оптическая (OM) и просвечивающая электронная микроскопия (ПЭМ), проведенные на микроскопах Olympus GX51 и JEM 200C соответственно; рентгеноструктурный фазовый анализ (РСФА) и дифференциальная сканирующая калориметрия, реализованные соответственно на дифрактометре ДРОН-3М (съемка в медном $K_{\alpha}$-излучении) и приборе синхронного термического анализа STA 449 (нагрев и охлаждение осуществляли в инертной атмосфере аргона); измерение микротвердости по Виккерсу проводили при нагрузке 1 Н с использованием приставки к микроскопу Neophot-2, определение модуля упругости осуществляли методом индентирования на установке CSM Instrument.

\section{3. Результаты и их обсуждение}

Металлографическое исследование структуры сплавов типа ВТ18У показало, что введение микродобавок изменяет внутризеренное строение (рис. 1). Для промышленного сплава 1, в основном, наблюдается структура типа корзиночного плетения (рис. $1 a$ ). В сплавах 2 и 3 с микродобавками такого рода структуры не получено (рис. $1 \mathrm{c}, e$ ). Фиксируемая микроструктура в этих сплавах глобулярно-пластинчатая и она более дисперсная по сравнению со сплавом 1. В ходе электронно-микроскопического исследования установлено, что во всех сплавах внутри $\alpha$-пластин происходит формирование полигональной структуры с образованием мелких субзерен (рис. $1 b, d, f$ ). Это свидетельствует о прохождении процессов полигонизации при отжиге $750{ }^{\circ} \mathrm{C}$ горячедеформированных сплавов.

Рентгенографическое исследование показало, что введение микродобавок приводит к увеличению количества $\beta$-фазы в сплавах 2 и 3 по сравнению со сплавом 1 . Если в сплаве 1 объемная доля $\beta$-фазы не превышает $5 \%$, то в сплаве 2 ее количество возрастает до $10 \%$. Кроме того, увеличение количества $\beta$-стабилизаторов в сплаве приводит к уменьшению ее параметра с 0,3272 нм в сплаве 1 до 0,3245 и 0,3240 нм соответственно для сплавов 2 и 3.

Микротвердость всех сплавов находится на близком уровне в пределах 3000-3150 МПа, очевидно, из-за компенсации вклада добавок в твердорастворное упрочнение увеличением объемной доли $\beta$-фазы в структуре. При этом модуль упругости как фазовочувствительная характеристика закономерно уменьшается по мере увеличения в структуре количества более низкомодульной $\beta$-фазы от сплава 1 (115 ГПа) к сплаву 3 (113 ГПа) и 2 (104 ГПа) 


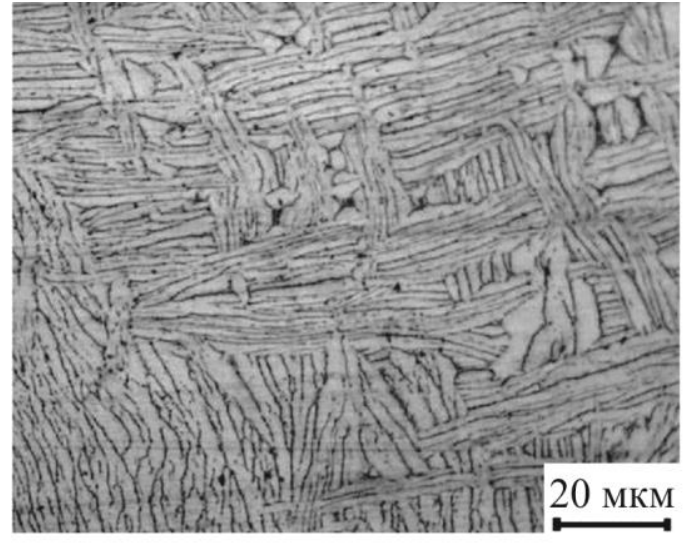

$a$

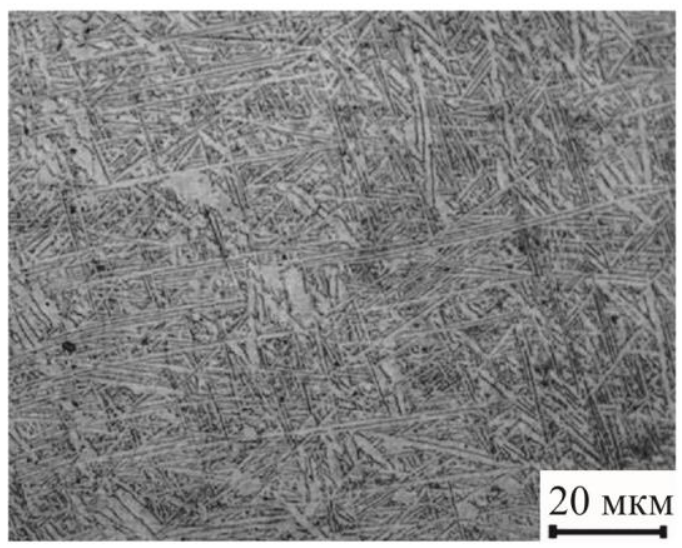

$c$

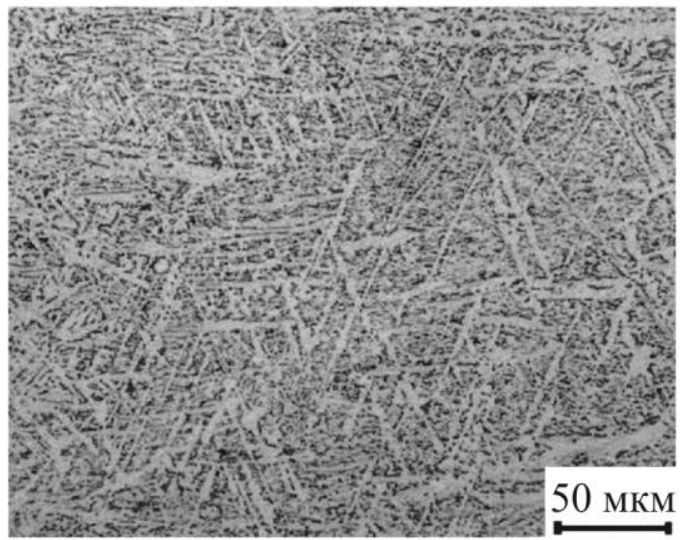

$e$

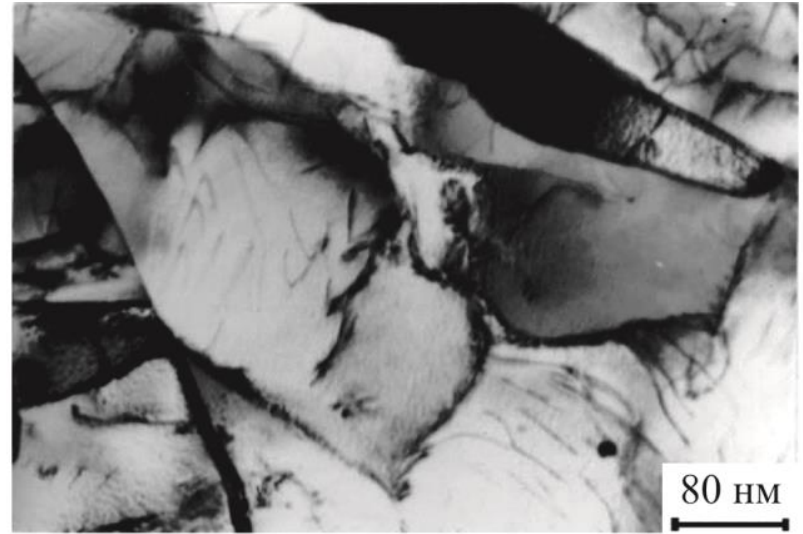

$b$

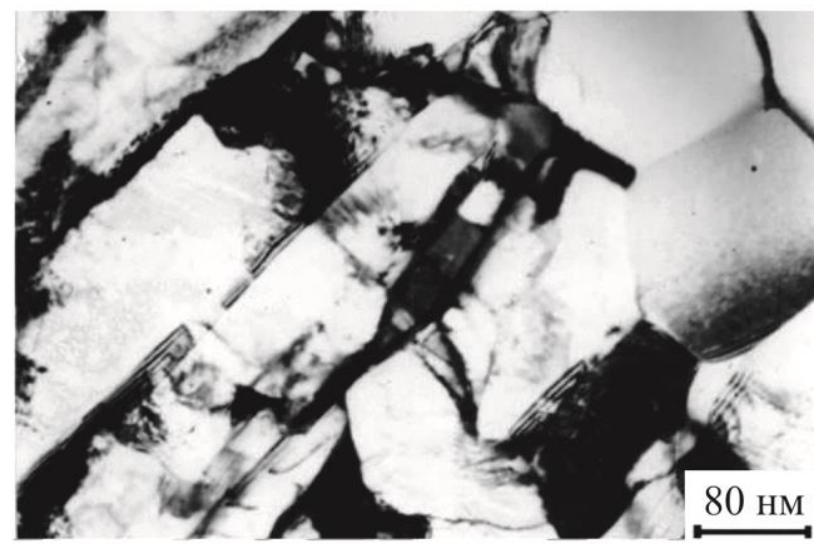

$d$

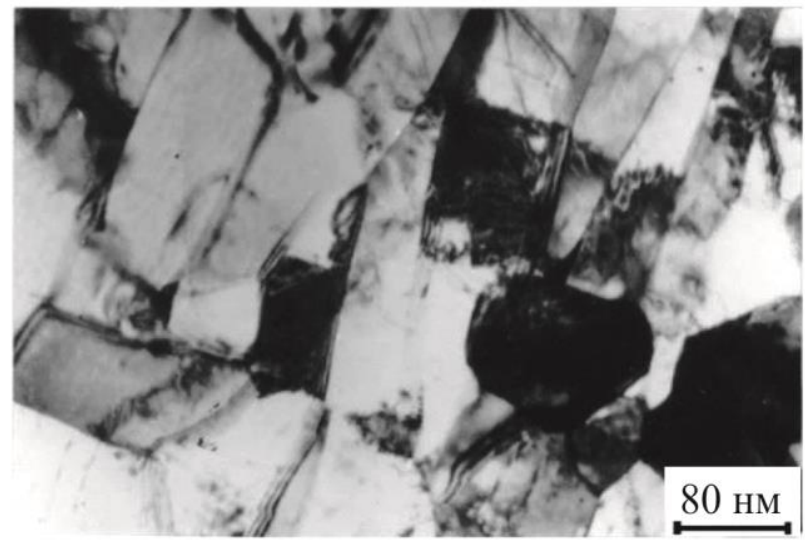

$f$

Рис. 1. Структура сплавов $1(a, b), 2(c, d)$ и $3(e, f)$ в исходном состоянии $(a, c, e)$ - световая микроскопия, $(b, d, e)-\Pi Э М$

Определение температуры полного полиморфного превращения методом термического анализа по пику производной в области эндоэффекта $\alpha+\beta \rightarrow \beta$-превращения в соответствии с методикой, описанной в работе [12], показало, что дополнительное легирование сплава ВТ18У влияет на положение температуры $\alpha+\beta \rightarrow \beta$-перехода $\left(T_{\text {пп }}\right)$ (рис. 2$)$. В промышленном сплаве 1 она равна $1013{ }^{\circ} \mathrm{C}$, а в сплавах 2 и $3-972{ }^{\circ} \mathrm{C}$ и $1001{ }^{\circ} \mathrm{C}$ соответственно. Видно, что увеличение $\beta$-стабилизаторов в сплаве ВТ18У за счет дополнительного легирования сопровождается смещением температуры $\alpha+\beta \rightarrow \beta$-перехода в область более низких температур. 


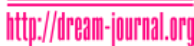

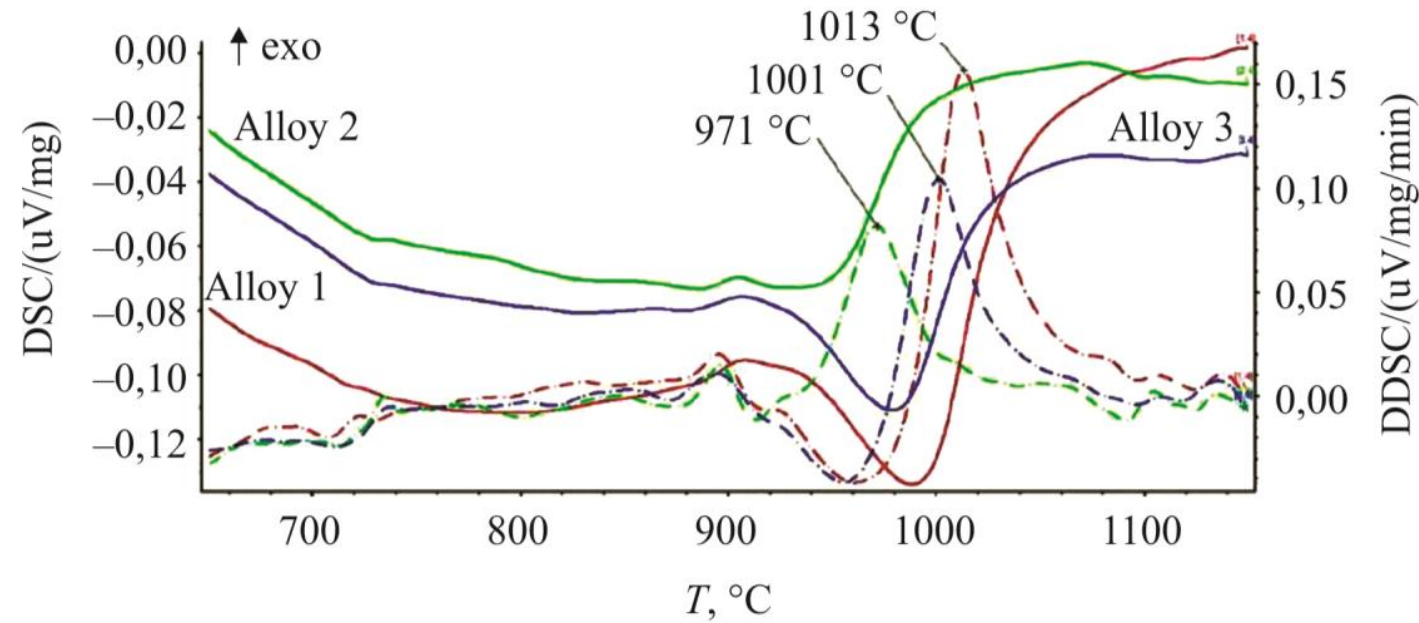

Рис. 2. Термограммы непрерывного нагрева и кривые производных ДСК сплавов

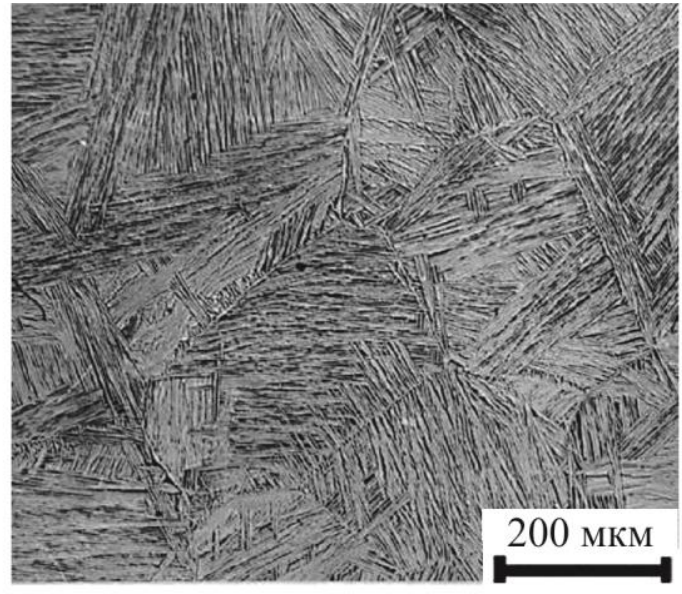

$a$

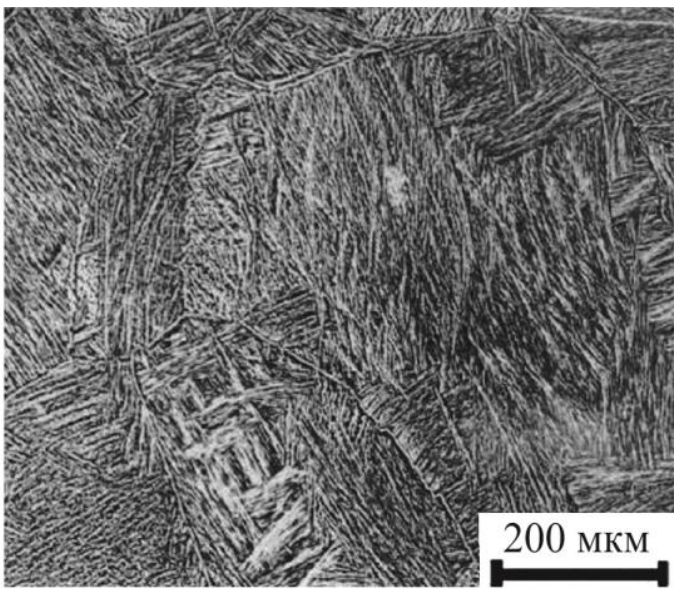

$b$

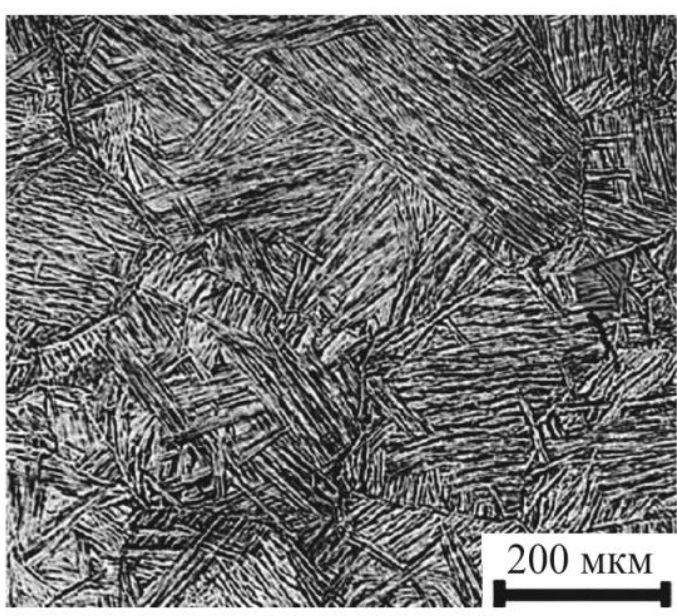

$c$

Рис. 3. Структура сплавов $1(a), 2(b), 3(c)$ после отжига $1050{ }^{\circ} \mathrm{C}, 1$ ч 
Для изучения влияния микродобавок на рост $\beta$-зерна в исследуемом сплаве был проведен отжиг в $\beta$-области при $1050{ }^{\circ} \mathrm{C}$ в течение 1 ч. После $\beta$-отжига в сплавах формируется структура, состоящая из пакетов крупных $\alpha$-пластин, которые растут преимущественно от границ $\beta$-превращенного зерна (рис. 3).

В пределах одного зерна может быть несколько пакетов $\alpha$-пластин, имеющих различную ориентировку. По границе $\beta$-зерна наблюдаются выделения зернограничной $\alpha$-фазы. Внутризеренная структура практически не изменяется от сплава к сплаву. В то же время дополнительное легирование влияет на средний размер $\beta$-превращенного зерна (табл. 1). Для сплавов 1 и 2 средний размер $\beta$-зерна отличается незначительно, а в сплаве 3 он в 2,6-2,8 раза меньше. Если учесть, что величина перегрева в $\beta$-область у сплава 2 примерно в 2 раза больше, чем у сплава 1, то можно сделать вывод, что добавки хрома и гафния в сплаве 2 несколько тормозят рост $\beta$-зерна. В то же время существенно более мелкое зерно в сплаве 3, на наш взгляд, в первую очередь связано с микролегированием сплава иттрием.

Таблица 1. Средний размер зерна, фазовый состав и микротвердость сплавов после $\beta$-отжига

\begin{tabular}{|c|c|c|c|}
\hline Сплав & $\begin{array}{c}\text { Средний размер } \\
\beta \text {-зерна, мкм }\end{array}$ & $\begin{array}{c}\text { Объемная доля } \\
\beta \text {-фазы, } \%\end{array}$ & $\begin{array}{c}\text { Микротвердость, } \\
\text { МПа }\end{array}$ \\
\hline 1 & $285 \pm 15$ & $3 \pm 1,0$ & $3900 \pm 100$ \\
\hline 2 & $265 \pm 15$ & $5 \pm 1,5$ & $3700 \pm 100$ \\
\hline 3 & $100 \pm 15$ & $7 \pm 1,5$ & $3500 \pm 100$ \\
\hline
\end{tabular}

В данном случае его действие можно объяснить с учетом того, что он является поверхностно-активным элементом. В этом случае главной причиной замедления роста $\beta$-зерна в сплаве 3 при $\beta$-отжиге является действие иттрия на подвижность границ за счет внутренней адсорбции на них. Причиной и стимулом укрупнения зерна при переходе в $\beta$-область является стремление поликристаллического тела к минимуму свободной энергии, в частности, путем уменьшения избыточной энергии границ.

Горофильная примесь, в нашем случае иттрий, обогащая границы, снижает их избыточную энергию и тем самым ослабляет стимул к росту зерна. Для того чтобы стимул к укрупнению зерен мог проявиться более активно необходимо повышение подвижности атомов, т. е. иттрий как бы повышает условную температуру начала интенсивного роста зерна. В целом можно сказать, что атомы иттрия, адсорбируясь на границах и двигаясь вместе с ней, закрепляют ее и тем самым тормозят ее движение.

Другие дополнительные легирующие добавки (хром, гафний) не являются такими сильными горофильными элементами, как иттрий и поэтому преимущественно находятся в твердом растворе, а не адсорбируются на границах. Следовательно, они не могут так же эффективно тормозить движение границ зерен и рост зерна при нагреве в $\beta$-область, что мы и фиксируем на примере сплава 2.

Рентгеноструктурный фазовый анализ показал, что после отжига в структуре сплава 1 присутствует практически одна стабильная $\alpha$-фаза со следами $\beta$-твердого раствора. Дополнительное легирование сплавов 2 и 3 , в первую очередь $\beta$-стабилизатором хромом приводит к увеличению количества $\beta$-фазы (табл. 1). Это в свою очередь отражается на микротвердости сплавов, которая уменьшается по мере возрастания объемной доли $\beta$-фазы в структуре от сплава 1 к сплаву 3. 


\section{4. Заключение}

Дополнительное легирование сплава 1 (ВТ18У) хромом с гафнием и хромом с иттрием обеспечивает снижение температуры $\alpha+\beta \rightarrow \beta$-перехода. Более высокое содержание $\beta$-стабилизаторов в опытных сплавах по сравнению с промышленным сплавом ВТ18У обеспечивает получение большего количества $\beta$-фазы в структуре и более низкий модуль упругости в состоянии после отжига в двухфазной $\alpha+\beta$-области $\left(750{ }^{\circ} \mathrm{C}\right)$.

После $\beta$-отжига при $1050{ }^{\circ} \mathrm{C}$ в течение 1 ч минимальный размер зерна фиксируется в сплаве, дополнительно легированном хромом и иттрием, что связано с действием иттрия как горофильной добавки, обогащающей $\beta$-границы, которая снижает их энергию, и тем самым способствующей замедлению их перемещения при нагреве в $\beta$-область. Дополнительное легирование хромом и гафнием модифицирующего эффекта практически не дает из-за отсутствия в паре (Cr, Hf) сильных горофильных элементов.

\section{Благодарность}

Работа выполнена при финансовой поддержке гранта РФФИ № 15-08-08299 А.

\section{Литература}

1. Хорев А. И. Теория и практика микролегирования псевдо- $\alpha-$ и $\alpha+\beta$-титановых сплавов РЗМ, цирконием, гафнием и рением // Технология машиностроения. - 2015. - № 1. - Р. 5-10.

2. Nochovnaya N. A., Khorev A. I., Yakovlev A. L. Perspectives of Alloying Titanium Alloys with Rare Earth Elements // Metal Science and Heat Treatment. - 2013. - Vol. 55, iss. 7-8. P. 415-418. - DOI: 10.1007/s11041-013-9646-0.

3. Characteristics of microstructures and second-phase particles in Y-bearing Ti-1100 alloy / W. F. Cui, C. M. Liu, L. Zhou, G. Z. Luo / Materials Science and Engineering A. - 2002. Vol. 323, iss. 1-2. - P. 192-197. - DOI: 10.1016/S0921-5093(01)01362-4.

4. Influence of rare earth element $\mathrm{Y}$ on the thermal stabilities of Ti-600 alloy / L. Zeng, Q. Hong, Y. Zhao, Y. Qi // Rare Metal Materials and Engineering. - 2014. - Vol. 43, no. 10. P. 2407-2410.

5. Huang Z. W. Thermal stability of Ti-44Al-4Nb-4Hf-0.2Si-1B alloy // Intermetallics. 2013. - Vol. 37. - P. 11-21. - DOI: 10.1016/j.intermet.2013.01.011.

6. Кащук В. А. Влияние переходных металлов на свойства металлов и сплавов. - Томск : Томский университет, 1981. - 272 с.

7. Терехова В. Ф., Савицкий Е. М. Иттрий. - Москва : Наука, 1967. - 270 с.

8. Khorev A. I. Alloying titanium alloys with rare-earth metals // Russian Engineering Research. - 2011. - Vol. 31, iss. 11. - P. 1087-1094. - DOI: 10.3103/S1068798X11110104.

9. Khorev A. I. Microalloying of titanium alloys // Metal Science and Heat Treatment. 1979. - Vol. 21, iss. 12. - P. 927-931. - DOI: 10.1007/BF00706629.

10. Influence of erbium and yttrium addition on the microstructure and mechanical properties of titanium alloys / B. B. Rath, B. A. McDonald, S. M. Sastry, R. Y. Lectench, G. E. O'Neal, C. R. Whitesett // 4th Int. Conf. on Titanium "Titanium 80", New York, 1980 : proceedings. New York, 1980. - P. 1185-1196.

11. Ильин А. А., Колачев Б. А., Полькин И. С. Титановые сплавы. Состав, структура, свойства : справочник. - Москва : ВИЛС-МАТИ, 2009. - 520 с.

12. Использование метода термического анализа для определения температуры полного полиморфного превращения двухфазного титанового сплава / Д. В. Гадеев, А. Г. Илларионов, А. А. Попов, М. А. Рыжков, Е. В. Колосова, М. А. Попова, П. С. Альтман, Н. Н. Бондарюк // Титан. - 2010. - Vol. 1. - P. 24-30. 